\title{
Surdez e família: facetas das relações parentais no cotidiano comunicativo bilíngue
}

\author{
Celeste Azulay Kelman \\ Universidade Federal do Rio de Janeiro \\ Daniele Nunes Henrique Silva \\ Ana Cecília Ferreira de Amorim \\ Rosa Maria Godinho Monteiro \\ Daisy Cristina Azevedo \\ Universidade de Brasília
}

\section{Resumo}

Esse artigo aborda a dinâmica familiar que envolve as diferenças no fluxo interativo entre filhos surdos e pais ouvintes e os aspectos educacionais presentes nesse contexto. Ressalta também as dimensões da subjetividade dos responsáveis ou representantes familiares. A metodologia empregada foi de caráter qualitativo, com a participação de dezoito familiares, que discutiram temas como: comunicação e linguagem, Libras e implante coclear. As categorias encontradas foram: Resistência/ Negação da surdez; Culpa/Responsabilidade pela surdez e Presença/Ausência da Língua de sinais na família. Pode-se concluir que programas de enfoque psicoeducacional, envolvendo experiências familiares, devem ser considerados prioritários na condução das políticas públicas, pois promovem a ressignificação de vivências, resultando no melhor desenvolvimento da criança.

Palavras-chave: Surdez. Família. Psicologia e educação. 


\section{Deafness and family: aspects of parental relationships in daily bilingual communication}

This article focuses on the familial dynamics of interactions between deaf children and hearing parents, as affected by the difference between them, and the educational aspects in this context. Emphasis is also placed on the subjectivities of the guardians or representatives of the families. A qualitative methodology was used, with the participation of eighteen family members, who discussed subjects such as: communication and language, sign language, and cochlear implants. The categories found were: resistance/ denial of deafness; guilt/responsibility for deafness, and presence/absence of sign language in the family. It can be concluded that programs with a psycho-educational focus, involving familial experiences, should be considered priorities in the conduction of public policies, for they promote the re-signification of experiences, resulting in better development of the child.

Keywords: : Deafness. Family. Psychology and education.

\section{Sordera y familia: Aspectos de las relaciones parentales en una esfera bilíngüe}

Este artículo presenta una dinámica familiar que trata de las diferencias en el flujo interactivo entre hijos sordos y padres oyentes y los aspectos educacionales presentes en este contexto. Se resalta también las dimensiones de la subjetividad de los responsables o representantes de la familia. La metodología aplicada fue de carácter cualitativo con la participación de dieciocho familiares, que han discutido temas como comunicación y lenguaje, lengua brasileña de señas y el implante coclear. Las categorías de esta investigación fueron: Resistencia/Negación de la sordera; Culpa/ Responsabilidad por la sordera y Presencia/Ausencia de la lengua de señas en la familia. Se puede concluir que programas psicoeducativos que tienen enfoque en las experiencias con las familias deben conducir las políticas públicas y tienen que ser una prioridad pues promueven nuevos significados de las experiencias haciendo con que los niños logren mejor desarrollo.

Palabras clave: Sordera. Familia. Psicología y educación. 


\section{Introdução}

Uma pessoa surda é aquela que vivencia um déficit de audição que a impede de adquirir, de maneira natural, a língua oral/auditiva usada pela comunidade majoritária. Dessa forma, ela se constitui a partir de estratégias cognitivas, de manifestações comportamentais e culturais diferentes da maioria das pessoas que ouvem (Behares, 1998).

De um modo geral, as causas da surdez são múltiplas, e os avanços tecnológicos para a detecção precoce da surdez e para a intervenção nesse processo são inegáveis. Porém, mesmo quando essa tecnologia é viabilizada ao surdo, ela não altera aspectos constitutivos do desenvolvimento sociocultural e linguístico do sujeito (Dizeu; Caporali, 2005). Ao contrário dos ouvintes, que utilizam a audição para se comunicar, os surdos se relacionam com o mundo por meio dos gestos e da visão e, por isso, seu desenvolvimento linguístico ocorre de um modo particular, por meio da língua de sinais, a sua língua natural (Cromack, 2004; Dizeu; Caporali, 2005). Nesse tipo de comunicação, a atenção, a percepção, a acuidade e memória visual são fatores fundamentais, bem como as expressões faciais, os movimentos labiais, os movimentos corporais etc.

A língua de sinais é a primeira língua do surdo, sendo fator definitivo de integração social e do desenvolvimento cognitivo. Somente por meio da língua de sinais é possível ao surdo ampliar suas interações com os seus pares, bem como ampliar sua penetração no universo cultural.

\section{O papel da língua de sinais na construção das funções psicológicas superiores}

Para Vigotski (1989), principal autor da perspectiva histórico-cultural, o problema central da surdez é a dificuldade do sujeito em se apropriar da palavra (falada) o que gera obstáculos para a sua inserção na cultura. De acordo com essa abordagem teórica, o signo é o instrumento psicológico essencial para o desenvolvimento das funções psicológicas superiores e o surdo fica à margem das experiências típicas com o seu meio social porque seus pares imediatos (pais e familiares), na maioria das vezes, não comungam do mesmo sistema de comunicação, pois são, geralmente, ouvintes. Essa situação de incompatibilidade comunicativa compromete o desenvolvimento cognitivo, sensível e social da criança surda (Silva, 2007).

Quando a criança ouvinte nasce, os pares familiares compõem o núcleo social no qual ocorrem os primeiros contatos e interações. Por meio deles, ela é envolvida pela esfera social e simbólica circundante, descobrindo o universo que a rodeia numa relação 
construída com a convivência. Seus pares significam, nomeiam, recortam o mundo e, nesse processo, ela vai se individualizando.

De acordo com as contribuições da perspectiva histórico-cultural, é por meio da internalização de complexos processos de conversão do social para o individual, mediados semioticamente, que se organiza e se estrutura o funcionamento psicológico. Ou seja, a partir das interações sociais e das práticas (trocas) coletivas, os sujeitos se tornam singulares e se desenvolvem.

A audição, por exemplo, é primordialmente o sentido por meio do qual a língua oral é aprendida e compartilhada, tornando-se suporte central para as interações sociais na sociedade oralizada. Nesse processo, a fala é detectada, reconhecida, interpretada e entendida, mantendo a significação sobre as atividades que estão ocorrendo no ambiente e os objetos nele contidos, trazendo sentido ao entorno cultural (Ines, 2005). Ouvir, portanto, constitui uma fonte fundamental de experiências sociais, de aceitação, para o sentimento de segurança pessoal de quem é ouvinte. Por isso, a não-aquisição do conteúdo oralizado faz com que o surdo tenha dificuldades para recortar os significados dispostos no mundo, já que ele não acessa amplamente o seu interlocutor, o que traz prejuízos ao seu desenvolvimento cognitivo e psicoafetivo.

A língua de sinais é o elemento simbólico central que permite ao surdo desenvolver todas as suas capacidades cognoscitivas (Almeida, 2009). Ela está para a criança surda assim como a língua oral está para a criança ouvinte: mediadora de processos de significação.

Os processos de internalização nos sujeitos surdos ocorrem, em princípio, de forma similar aos das pessoas ouvintes, por meio da apropriação de significações vivenciadas nas dinâmicas culturais, levando a um desenvolvimento integrado. No entanto, para que esses processos ocorram é necessário que o surdo tenha a possibilidade de estabelecer relações com seus pares o mais precocemente possível, na medida em que estes compartilham do mesmo canal linguístico. Sobre isso, Góes (2000, p. 48) argumenta: "torna-se fundamental o contraponto dado pela comunidade de surdos que permite a criança significar-se como surdo e como sujeito que enuncia numa língua efetiva a qual tem características próprias e configura-se como fonte de identidade".

A interação com os adultos e colegas mais velhos, que utilizam a língua de sinais, desempenha um papel importante na formação e organização do pensamento complexo e abstrato individual do surdo, da mesma forma como a utilização da língua oral para os ouvintes. Vários pesquisadores apontam a relevância da língua de sinais como fator decisivo na inclusão social (Lacerda; Silva, 2006). Daí vem a necessidade do contato precoce da criança com a língua de sinais, seja na presença de um adulto surdo, ou de um adulto sinalizante fluente, especialmente quando pais e mães são ouvintes.

Observa-se que a aquisição tardia da língua de sinais pode acarretar prejuízos ao desenvolvimento no que tange à constituição subjetiva, bem como trazer dificuldades 
em solucionar problemas e retração nas práticas socializadoras: Falar o quê? Com quem? No entanto, a criança surda, ao longo da ontogênese, interage em diferentes esferas comunicativas. Sem dúvida, a experiência com ouvintes e o contato com a comunidade surda convergem para uma vivência linguística de configuração identitária bastante peculiar, principalmente quando se assume centralmente a relação ente língua de sinais, cultura e funcionamento psicológico superior.

Nesse sentido, o modo como a criança se insere nessas dinâmicas discursivas é fundamental para se entender aspectos de sua identidade. Conhecer como as famílias (primeiro núcleo social) integram e vivenciam a língua de sinais nas suas práticas cotidianas é importante para constituição do surdo, principalmente quando se considera que a família é, na maioria dos casos, composta por membros ouvintes.

\section{Família e Surdez}

A família constitui a esfera em que ocorrem os primeiros contatos e trocas sociais de uma criança. Assim sendo, o núcleo familiar é o local no qual emergem os vínculos comunicacionais primários, constituídos de significados e sentidos absorvidos por meio da internalização das trocas dialógicas, possibilitando o desenvolvimento do pensamento.

Segundo Hinde (1987 apud Dessen; Silva, 2004), o desenvolvimento do indivíduo depende crucialmente das relações que ele estabelece com os outros, cujas influências são internalizadas, afetando seu comportamento manifesto. Os valores, as normas e outros aspectos da estrutura sociocultural tornam-se, então, parte dos indivíduos. No entanto, para que esses vínculos sejam estabelecidos de modo eficaz, tanto no que concerne aos significados quanto ao desenvolvimento psicoafetivo e cognitivo, é necessário que pais e filhos (com)partilhem do mesmo canal de comunicação.

Mesmo que estudos indiquem que as relações entre genitores ouvintes e crianças surdas apresentam uma alta probabilidade de diminuição nas interações, devido às dificuldades de comunicação, é importante que os pais continuem mantendo o contato visual com seus filhos, para que seja estabelecido o sentimento de segurança na criança (Brito; Dessen, 1999). Sabe-se que na comunicação expressões faciais e corporais também são utilizadas como forma de viabilizar a compreensão daquilo que se pretende dizer (Ines, 2005).

Estudos estatísticos demonstram que cerca de 0,1\% das crianças nascem com perda auditiva severa ou profunda, e $95 \%$ dessas crianças são filhas de pais ouvintes (Almeida, 2009). 0 diagnóstico de surdez leva a maioria das famílias, num primeiro momento, ao sentimento de luto pela morte simbólica de seu filho idealizado. A partir daí, a forma 
como cada membro familiar irá vivenciar a experiência da surdez influenciará na constituição e no desenvolvimento cognitivo e afetivo do sujeito surdo.

Os genitores, ao serem notificados que tiveram um bebê com uma "deficiência auditiva" (termo clinicamente utilizado para definir a surdez), com possibilidades de atraso no desenvolvimento, frequentemente enfrentam períodos difíceis, especialmente no que tange às interações com seus bebês, devido a fatores emocionais. Inicialmente existe um momento de choque, em seguida, tristeza ou ansiedade e, gradualmente, ocorre uma reorganização na direção da aceitação do bebê (Taveira, 1995). As mães experienciam um sentimento de choque e descrença, reação inicial de crise. Esse período pode ser acompanhado de depressão e desorganização emocional. Com o tempo, os pais e mães adaptam-se para tentar ajudar a criança que tem deficiência e, paulatinamente, atingem o estágio de organização emocional.

Os pais e mães desempenham o papel de responsáveis pela sintonia estabelecida com a criança e também por facilitar as trocas comunicativas. No processo de aquisição da linguagem, a adequação mútua nas conversações mantidas sobre os objetos, a troca de olhares, gestos e expressões e a incorporação da língualgem) da criança surda por parte do adulto são alguns dos elementos que contribuem para o estabelecimento de uma experiência comunicativa fluente e satisfatória (Brito; Dessen, 1999).

As mães de surdos desempenham um papel ativo na promoção do bem-estar e melhor preparo de seus filhos, investindo na promoção da inclusão e sendo agentes no acesso e desenvolvimento das crianças (Kelman; Faria, 2007). Contudo, é importante indagar: Como os pais/mães/responsáveis significam a surdez e se posicionam diante do surdo? Como estabelecem o vínculo comunicacional? Pensar sobre essas questões envolve refletir, por exemplo, sobre a qualidade da relação entre pais e mães ouvintes e filhos surdos, já que a surdez se caracteriza, muitas vezes, pela dificuldade comunicativa, trazendo consequências de ordem afetiva e cognitiva.

\section{Procedimentos de investigação}

Famílias com crianças surdas necessitam interagir com outros pais e mães que vivem a mesma situação há mais tempo, de forma a poderem internalizar modos de criar vínculos afetivos e comunicacionais com seus filhos. Apesar de a literatura relatar pesquisas que estudam as falas de pais e mães sobre seus filhos, ainda é escassa a produção de conhecimento na área, o que gera a necessidade de realização de novas pesquisas (Barbato, 2008) principalmente no que se refere à fala de pais e mães de crianças surdas. 
0 presente estudo adota uma análise qualitativa das interações humanas, utilizando o seu caráter compreensivo e interpretativo. Segundo González Rey (2002), a construção de conhecimento ocorre a partir do diálogo, buscando compreender uma realidade que é plurideterminada, diferenciada, irregular, interativa e histórica. Pesquisas dessa ordem partem do pressuposto de que os dados da realidade são construídos a partir da interação do pesquisador com os participantes da pesquisa. Desse modo, o conhecimento é visto como produção e não (somente) apropriação de uma realidade (González Rey, 2005).

Nesse sentido, foi necessário fazer uma imersão no contexto em que ocorreu essa pesquisa, o que permitiu perceber as crenças, atitudes, percepções, valores e sentimentos que configuram o modo de agir dos familiares pesquisados. Com a convivência, o contato periódico, o compartilhar das angústias, desejos e motivações desses familiares foram desvelados. Para Kelman (2006, p. 41), as pesquisas realizadas na perspectiva qualitativa têm a "peculiaridade da dialética, da não permanência e não universalização, justamente porque levam em consideração o fator histórico e a sua temporalidade". Por entender-se que a verdade é temporária e circunscrita às circunstâncias da pesquisa, esse estudo não tem a pretensão de possibilitar uma generalização, e sim de permitir novas articulações com outros campos, outros olhares, novas produções teóricas, realimentando o processo investigativo.

\section{Caracterizando o espaço da pesquisa}

Esse estudo foi desenvolvido no ano de 2009 no Centro de Apoio ao Surdo (CAS) localizado em Brasília. O CAS é o resultado de uma parceria entre a Secretaria de Estado de Educação do Distrito Federal e o Ministério da Educação. Neste convênio, os professores pertencem aos quadros da SEEd/DF.

O CAS tem como missão fornecer cursos de formação continuada para professores e professoras da rede, além de funcionar como centro de apoio pedagógico não apenas a alunos surdos, mas também a alunos com Dificuldades no Processamento Auditivo Central (DPAC) ou que tenham alguma outra deficiência associada à surdez. Todos os alunos estudam em escolas inclusivas da rede regular de ensino e recebem apoio pedagógico do CAS no turno contrário. Uma das características do CAS é de oferecer cursos de língua de sinais para os professores da rede e também para pais e mães de alunos que permanecem nas suas dependências enquanto seus filhos têm o reforço pedagógico e demais atividades oferecidas, como aulas de lógica, xadrez e informática. Com o propósito de dar continuidade a um projeto previamente desenvolvido pela Universidade de Brasília (Kelman; Faria, 2007), reiniciou-se a pesquisa no atendimento aos responsáveis que levam seus filhos ou parentes ao CAS duas vezes por semana. 
0 projeto iniciou dentro de uma perspectiva interdisciplinar entre a Faculdade de Educação e o Instituto de Psicologia, da Universidade de Brasília. Nessa linha, o enfoque investigativo levou em consideração os aspectos envolvidos na dinâmica familiar em interface com os problemas educacionais experimentados pelos alunos surdos, investigando dimensões da subjetividade de seus responsáveis ou representantes familiares.

Assim, participaram dessa pesquisa duas professoras dos cursos (Psicologia e Pedagogia/UnB), duas psicólogas voluntárias (com tempo de formação superior a três anos) e quatro estudantes de graduação em Pedagogia (duas das quais já estavam previamente envolvidas com um projeto que abordava aspectos educacionais de alunos surdos, desenvolvido pela primeira autora desse artigol. Os participantes envolvidos na pesquisa foram divididos em dois grupos, em função do horário que levavam seus filhos para as atividades de reforço pedagógico e outras oferecidas pelo CAS. Foram um total de 18 participantes (total do grupo da manhã e do grupo da tarde) e que não necessariamente eram os responsáveis diretos pelo aluno surdo, mas a pessoa que levava e aguardava o aluno enquanto este realizava suas atividades acadêmicas. 0 quadro a seguir identifica os sujeitos participantes com nomes fictícios, sua relação de parentesco com o aluno surdo e as características que o aluno apresenta.

\section{Quadro 1 - Sujeitos da pesquisa}

\begin{tabular}{|l|l|l|}
\hline Nome fictício & Grau de parentesco & Características do aluno \\
\hline Marina & Mãe & Surdez Profunda e Deficiência Intelectual \\
\hline Luana & Mãe & Surdez Profunda e Paralisia Cerebral \\
\hline Glenda & Avó & DPAC - Distúrbio do Processamento Auditivo Central \\
\hline Sílvia & Mãe & Surdez Profunda e Atraso Motor \\
\hline Vanda & Mãe & Surdez Profunda e Paralisia Cerebral \\
\hline Daiane & Irmã & Surdez Profunda e Paralisia Cerebral \\
\hline Marcela & Mãe & $\begin{array}{l}\text { Surdez Profunda, Paralisia Cerebral, Deficiência } \\
\text { Intelectual, Lado direito comprometido }\end{array}$ \\
\hline Wanda & Mãe & Surdez Profunda unilateral \\
\hline João & Tio & Surdez bilateral \\
\hline Maria & Mãe & Surdez bilateral \\
\hline Edna & Mãe & Surdez Moderada \\
\hline Lourdes & Mãe & Surdez bilateral \\
\hline Júlia & Mãe & Surdez bilateral \\
\hline
\end{tabular}


Quadro 1 - continuação

\begin{tabular}{|l|l|l|}
\hline Nome fictício & Grau de parentesco & Características do aluno \\
\hline lara & Mãe & DPAC \\
\hline Silvia & Mãe & Surdez bilateral \\
\hline Aline & Mãe & DPAC e surdez unilateral \\
\hline Pedro & Pai & Surdez bilateral \\
\hline Úrsula & Mãe & DPAC \\
\hline
\end{tabular}

0 trabalho de registro dos dados foi organizado de forma a capturar diferentes momentos de interação do pesquisador/responsável familiar e os responsáveis entre si, por meio do uso de gravador e diário de campo. As falas sussurradas entre os pares em interação, as trocas de olhares e minuciosas expressões corporais, que configuravam parte importante da composição dos dados, foram registradas na articulação do que era captado pelo gravador com as anotações de campo para posterior transcrição e análise. A composição desses registros buscava, na estruturação de um texto final (referente a cada dia de investigação), identificar situações específicas dos conflitos vivenciados pelos participantes da pesquisa. As dinâmicas enunciativas era focadas como elementos centrais para se entender como os participantes significavam a surdez, qual papel atribuíam a Língua de Sinais e quais as dificuldades que encontravam na relação com os aspectos formativos dos surdos.

A pesquisa ocorreu em seis encontros do Grupo A e quatro encontros do Grupo B. Cada sessão desenvolveu-se em aproximadamente 1 hora e 40 minutos de duração com seis pesquisadoras fazendo revezamento: dividiram-se em dois grupos, para que ocorressem as reuniões pelo período da manhã e da tarde. As três pesquisadoras, também, alternavam-se na coleta dos dados e, a cada encontro, uma pesquisadora era responsável por conduzir a reunião, a outra pelas anotações e confecção do diário de campo e a terceira pela audiogravação, para que pudesse fazer a transcrição. Os temas abordados estarão descritos no quadro 2 los participantes do grupo A referem-se ao grupo da manhã, e o grupo B refere-se ao do período da tarde): 
Quadro 2 - Temáticas abordadas

\begin{tabular}{|c|c|c|}
\hline Temas & Objetivos & Participantes \\
\hline $\begin{array}{l}\text { Apresentação do } \\
\text { Projeto }\end{array}$ & $\begin{array}{l}\text { - Apresentar as pesquisadoras e o projeto } \\
\text { - Colher a autorização de áudio e informações } \\
\text { - Conhecer o grupo }\end{array}$ & $\begin{array}{l}\text { GRUPO A: } 4 \\
\text { GRUPO B: } 8\end{array}$ \\
\hline 0 que é surdez? & $\begin{array}{l}\text { - Diferenciar surdez e DPAC } \\
\text { - Explicar: a anatomia do ouvido, tipos e graus da } \\
\text { surdez } \\
\text { - Discutir sobre o diagnóstico tardio }\end{array}$ & $\begin{array}{l}\text { GRUPO A: } 7 \\
\text { GRUPO B: } 5\end{array}$ \\
\hline $\begin{array}{l}\text { Comunicação e } \\
\text { Linguagem }\end{array}$ & $\begin{array}{l}\text { - Demonstrar os desafios da comunicação com o } \\
\text { surdo } \\
\text { - Demonstrar como o surdo compreende o mundo } \\
\text { pela linguagem } \\
\text { - Demonstrar as diferenças das línguas: Lo (língua } \\
\text { oral auditiva) e LS (gestual visual) } \\
\text { - Demonstrar a importância da LS: relação } \\
\text { pensamento e linguagem; não é universal, } \\
\text { nem artificial (não é um artifício, é condição) }\end{array}$ & $\begin{array}{l}\text { GRUPO A: } 5 \\
\text { GRUPO B: } 7\end{array}$ \\
\hline Libras & $\begin{array}{l}\text { - Fornecer informações básicas sobre a língua de } \\
\text { sinais: a língua natural do surdo; os fonemas } \\
\text { (configuração de mão, ponto de articulação, } \\
\text { movimento, expressões não-manuais e orientação } \\
\text { das mãos) } \\
\text { - Informações sobre a importância da língua de } \\
\text { sinais no desenvolvimento do surdo } \\
\text { - Definição de bilinguismo e a sua importância } \\
\text { - Explicar o que é e quais os objetivos do decreto } \\
\text { de acessibilidade } \\
\text { - Informar e esclarecer sobre a cirurgia de } \\
\text { implante coclear, colocando suas reais impli- } \\
\text { cações, na tentativa de evitar fantasias de cura }\end{array}$ & $\begin{array}{l}\text { GRUPO A: } 6 \\
\text { GRUPO B: } 8\end{array}$ \\
\hline $\begin{array}{l}\text { Surdo adulto } \\
\text { como convidado }\end{array}$ & $\begin{array}{l}\text { - Promover a oportunidade de debaterem assuntos } \\
\text { sobre a educação atual e o futuro de seus } \\
\text { filhos/parentes surdos tais como as dificuldades } \\
\text { encontradas no processo de educação, vestibular, } \\
\text { mercado de trabalho, namoro, casamento. }\end{array}$ & $\begin{array}{l}\text { GRUPO A: } 6 \\
\text { GRUPO B: (não } \\
\text { compareceu } \\
\text { esse encontro) }\end{array}$ \\
\hline $\begin{array}{l}\text { Finalização dos } \\
\text { Encontros de } \\
2009\end{array}$ & $\begin{array}{l}\text { - Mobilizar os participantes a refletir sobre os } \\
\text { encontros }\end{array}$ & $\begin{array}{l}\text { GRUPO A: } 6 \\
\text { GRUPO B: (não } \\
\text { compareceu } \\
\text { esse encontro) }\end{array}$ \\
\hline
\end{tabular}


Com base nos dados analisados identificamos três posições dos mães/pais/ responsáveis em relação aos seus filhos surdos, em especial nos aspectos referentes às experiências comunicativas: a) Resistência/negação da surdez por seus familiares; b) Culpa/responsabilidade pela surdez, c) Presença/ausência da língua de sinais na família.

\section{a) Resistência/negação da surdez por seus familiares}

Conforme destacado por Ribeiro (2007), a resistência representa um mecanismo de defesa. É um processo humano que ocorre quando o indivíduo se encontra sob algum tipo de ameaça. Fadiman e Frager (1986) apontam que o mecanismo de defesa é uma possível forma de se defender contra ansiedade, deformando ou negando a própria situação. Em síntese, de acordo com esses autores, o sujeito se defende da realidade atrasando seu reconhecimento ou captando-o de maneira distorcida. A negação é a tentativa de não aceitar um fato perturbador da realidade.

Em muitos momentos da investigação, observamos que os integrantes do grupo apresentavam atitudes de resistências/impedimentos às discussões que estavam sendo desenvolvidas sobre a importância da língua de sinais. Lourdes (mãe de um adolescente surdo profundo), por exemplo, raramente participava das discussões do grupo, alegando não ter tempo para aprender Libras em função das exigências cotidianas da vida doméstica. Ela comenta:

Só que é aquela coisa, eu não tenho muito tempo pra estudar em casa, como eu sou sozinha, sou mãe e pai dos meus filhos, fica um pouco difícil até pra mim aprender alguma coisa. Porque eu tenho vontade de estudar um pouco em casa, mas é aquela coisa, eu não tenho tempo. Aí fica difícil! (Depoimento transcrito, 25/10/09)

Durante os encontros, seu posicionamento era de pouca interação quando o assunto era a surdez; muitas vezes dispersava as outras mães com assuntos alheios. No último encontro, uma das pesquisadoras recomendou o filme 'O Milagre de Anne Sullivan' para ser visto pelas mães. Marcia, com dúvida sobre como escrever corretamente o nome do filme, pede auxílio ortográfico à pesquisadora. Lourdes pergunta:

0 que é isso aí? - referindo-se a escrita da pesquisadora.

Marcia explica:

- É o nome do filme.

Lourdes ri ironicamente, empurrando o caderno:

- Para que isso aí?! 
Lourdes revela sua dificuldade em refletir sobre a experiência de ter um filho surdo. Além disso, demonstra um incômodo com relação à não-aprendizagem de Libras, aspecto muito criticado pelo filho. Ela narra:

Você acredita que o meu menino chegou uma vez a me chamar de burra [por desconhecer os sinais]? Às vezes, ele falava comigo e eu não entendia. 0 meu menino uma vez já chegou a me chamar de burra. Ele fala as coisas comigo e eu não entendo, aí ele vai lá pega o lápis e escreve a coisa pra mim. Não é fácil mesmo não. Às vezes eu consigo entender... Não precisa dele escrever, ele tentando, aí eu vou... (Depoimento transcrito, $21 / 10 / 2009)$.

É possível verificar que a resistência de Lourdes impede uma comunicação adequada com o filho, prejudicando o estreitamento de relações que ocorreriam caso falassem a mesma língua. 0 fato de Lourdes rejeitar a língua de seu filho é vista por ele como indicador de agressão pessoal e reage chamando-a de burra.

\section{b) Culpa/responsabilidade pela surdez}

A culpa é um outro elemento para as questões levantadas pelas mães/responsáveis na relação com seus respectivos filhos. Em vários momentos elas tentavam explicar, através de suas atitudes, o porquê de terem tido uma criança que tem deficiência, relembrando, por exemplo, as situações em que poderiam ter tomado posturas diferentes com relação aos filhos, o que supostamente evitaria a surdez.

Nesse sentido, Julia comenta sobre o fato de sua filha ter passado um mês no hospital após o nascimento. Ela acredita que a pneumonia da recém-nascida teria causado a surdez. Ela narra: "Eu fiz o pré-natal dela em Pernambuco [...] acho que isso contribuiu?" (Depoimento transcrito, 30/09/2009).

Na primeira reunião, quando questionada sobre as relações familiares, Lourdes conta que teve apenas o apoio de sua mãe. Coloca também que sofria violência pelo ex-marido durante a gestação e acredita que a surdez de seu filho seja consequência de situações estressantes (violência do pai da criança) que passou durante a gravidez. Ela narra: "Eu passei muito nervoso durante a minha gravidez, pode ter sido por isso... sofri muito, meu ex-marido me passava muita raiva, eu ficava muito nervosa" (diário de campo, 16/09/2009).

Atribuir a surdez à violência sofrida pode ser uma tentativa de eximir-se de qualquer responsabilidade, minorando o sentimento de culpa pela surdez do filho. A dificuldade em perceber que as causas da surdez independem dos comportamentos do pai ou da mãe foi melhor compreendida na medida em que as possibilidades diagnósticas foram apresentadas e comentadas no grupo, diminuindo o sentimento de culpa presente. 


\section{c) Presença/ausência da Língua de sinais na família}

Goldfeld (1997) ressalta que, no decorrer do desenvolvimento infantil, a criança passa por diversas mudanças, e a língua é um dos principais instrumentos que permeiam esse processo. Para a criança surda, portanto, esse processo de desenvolvimento pode ficar fragmentado, pois ela não poderá aprender a língua oral de forma espontânea, como a criança ouvinte. Nesse sentido, a aquisição da língua de sinais vai permitir à criança surda, mediante suas relações sociais, o acesso aos conceitos de sua comunidade, os quais passará a utilizar como seus, formando assim uma maneira de pensar, agir e ver o mundo característico da cultura de sua comunidade.

Ainda há um grande preconceito com a língua de sinais pelo fato dela não ser oral. Existem crenças equivocadas de que é apenas mímicas ou gestos. Essa concepção é hegemônica e aparece nas falas dos pais/responsáveis. Em um dos relatos, Júlia descreve a língua de sinais com certo descaso, afirmando sempre concordar quando a filha perguntava algo em Libras, sem se preocupar com o que ela estava querendo dizer. Certa vez, a criança perguntou se poderia bater em um colega. Júlia (sem se interessar em saber o que sua filha dizial concordou. No dia seguinte, recebeu o bilhete da professora pontuando a atitude agressiva da menina no colégio. Então, Júlia se deu conta de que precisava estudar mais a língua de sinais para entender sua filha:

Uma vez quando a minha menina estudava lá no colégio, ela chegou e brigou com um menino na escola, aí o menino cuspiu na cabeça dela, ela chegou em casa e me falou que quando chegasse lá ia bater nele, eu não sabia o que era, ela falou ... eu falei vai.. vai..! [fazendo gestos com as mãos mandando ir]. Quando foi no outro dia... ela foi pra escola. Aí, pegou o menino e deu nele e rasgou a camisa dele. Aí, ela chegou. Aí a professora mandou um bilhete pra mim e disse que ela disse que eu tinha mandado ela bater no menino e rasgar a camisa (risos). Aí a mãe dele falou que queria uma camisa nova [...] porque a mãe tinha mandado ela brigar com o menino e bater nele e rasgar a camisa. Agora, tem que falar com a mãe (Depoimento transcrito em 21/10/2009).

Um outro caso a ser exemplificado nesta categoria é o de Silvia, mãe de um adolescente surdo que estuda na terceira série do ensino fundamental. Ela alega estudar Libras e diz que pretende tornar-se intérprete de Libras. Em encontro posterior, em que foram abordadas algumas considerações sobre aparelho de amplificacão sonora e implante coclear, Silvia diz que seu filho chegou a frequentar a instituição CEAL (Centro Educacional de Audição e Linguagem Ludovico Pavoni - DF), mas mesmo assim não se sentiu mobilizada a buscar informações sobre implante, pois poderia não dar certo e ser mais uma decepção em sua vida ljá que o diagnóstico de seu filho foi decepcionante - diário de campo, 04/11/2009). A frustração na comunicação com o seu filho 
colaborou para que Silvia tivesse escolhido a língua de sinais como canal central para interagir com o seu filho. Ela, de fato, não sabia a importância de Libras para a educação e desenvolvimento de seu filho, mas apostou nas respostas diárias que ele apresentava em sua comunicação com ela nessa língua.

Segundo Luria (1986), os processos de desenvolvimento do pensamento e da linguagem incluem o conjunto de interações entre a criança e o ambiente, podendo ser afetados, positiva ou negativamente, pela qualidade dessas interações. Isso sugere que a postura que a família toma em relação à Língua de sinais influencia diretamente o desenvolvimento da criança surda.

\section{Considerações finais}

A pesquisa revelou que nenhuma família deseja ou espera conceber uma criança diferente. Ainda impera a visão de que um cidadão bem sucedido é aquele que não apresenta deficiência alguma. Em geral, a chegada do bebê que apresenta uma deficiência torna-se um evento traumático e desestruturador, que interrompe o equilíbrio familiar, uma vez que antes do nascimento a criança é idealizada e sonhada. A família faz projetos para o seu futuro de acordo com os próprios conteúdos emocionais e desejos, o que é desestruturado com a presença de uma deficiência.

Diante desse fato, pais e mães apresentam a necessidade de uma reestruturação pessoal e familiar, na qual possam trabalhar as emoções e os sentimentos em relação a esse filho ou filha. No acompanhamento investigativo do presente estudo, percebeuse que a figura materna é responsabilizada pelo cuidado desse filho surdo, no que diz respeito à aprendizagem da língua de sinais, na educação e no bem-estar geral da criança.

Pode-se observar que o tema da surdez, como espaço de problematização da relação mãe-filho, é perturbador para algumas mães. Há uma resistência em aprofundar o conhecimento sobre o tema, o que pode indicar a dificuldade das mães em lidarem com o sofrimento de ter um filho em condições culturais e linguísticas adversas. Evitar o assunto, alterar rotas discursivas sobre o filho surdo é um forma de se defender da dor cotidiana de tê-lo, bem como de todas as dificuldades operacionais, econômicas e sociais que implicam a presença de uma criança com desenvolvimento atípico.

A forma de dar acolhimento e sentido à dor está na culpa. Ela é o mote principal para explicar (para si - mãe) a situação da surdez do filho. A culpa é uma construção narrativa (in)tranquila, em que a mãe se explica (produz um sentido) sobre uma situação inesperada e indesejável. 0 relato de Julia (semelhante a outros relatos) é 
contundente nesse sentido. Pode-se inferir, extrapolando as categorias apresentadas, que a mãe-culpada (por uma suposta negligência por ela assumida) consolida, na dinâmica das interações, a criança-vítima. Essa polaridade reforça uma experiência materna de superproteção, que dificulta (e, muitas vezes, impede) a autonomia do filho. As mães relatam que têm medo de as crianças serem atropeladas ou de se envolverem em situações de risco, o que justifica a intensa dedicação.

Todos esses aspectos, somados às questões comunicativas que implicam na aceitação e no uso de Libras no cotidiano familiar, fazem com que os interesses sobre a família de crianças surdas se torne prioritário na condução das políticas públicas. Ou seja, o acompanhamento de familiares de crianças surdas não pode ser meramente informativo (conteudístico) sobre questões gerais da surdez. Precisa, sim, acolher questões de relações parentais, que necessitam de intervenções psicológicas e formativas mais profundas. Nesse sentido, um enfoque psicoeducacional pode ser mais produtivo e significativo para mães, pais, responsáveis e filhos/filhas, especialmente, por envolver experiências em grupo em que as situações individuais são compartilhadas (ressignificadas) na esfera coletiva.

\section{Referências}

ALMEIDA, Maria José Freire. 0 desenvolvimento da literacia na criança surda: Uma abordagem centrada na família para uma intervenção precoce. Revista online Mediações, v. 1, n. 1, 2009.

BARBATO, Silviane. Metodologia de Pesquisa Qualitativa (módulo 6). Universidade de Brasília, 2008. BEHARES, Luis Ernesto (Org.). Segundo Seminario sobre Educación y Lenguaje en Áreas de Frontera. Universidad de la República, Montevideo: Gabaratoss.s.r.l. 1998

BRITO, Angela Maria Waked de; DESSEN, Maria Auxiliadora. Crianças surdas e suas famílias: um panorama geral. Psicologia: Reflexão e Crítica, v. 12, p. 429-445, 1999.

CROMACK, Eliane Maria Polidoro da Costa. Identidades, cultura surda e produção de subjetividades e educação. Psicologia, Ciência e Profissão, Brasília, v. 24 n. 4, 2004.

DESSEN, Maria Auxiliadora; SILVA, Nara Liana Pereira. A família e os programas de intervenção: tendências atuais. In: MENDES, Enicéia. Temas em Educação Especial. São Carlos: EdUFSCar, p. 179$18,2004$.

DIZEU, Liliane Correia Toscano. de Brito e CAPORALI, Sueli Aparecida. A Língua de Sinais Constituindo o Surdo como Sujeito. Educação e Sociedade, vol. 26, n. 91, p. 583-597, 2005.

FADIMAN, James e FRAGER, Robert. Teorias da personalidade. São Paulo: Harbra, 1986.

GÓES, Maria Cecília Rafael de. Com quem as crianças surdas dialogam em sinais? In: FEITOSA, Cristina Broglia Feitosa; GÓES, Maria Cecília Rafael de (Org.). Surdez: processos educativos e subjetividade. Lovise: São Paulo, 2000. p. 29-49. 
GOLDFELD, Márcia. Criança Surda: linguagem e cognição numa perspectiva socio-interacionista. São Paulo: Plexus, 1997.

GONZÁLEZ REY, Fernando. Pesquisa qualitativa em Psicologia: caminhos e desafios. São Paulo: Thomson, 2002.

. Pesquisa Qualitativa e Subjetividade: os processos de construção da informação. São Paulo:

Thomson, 2005

INES. Instituto Nacional de Educação de Surdos. Série Audiologia. Edição Revisada. Rio de Janeiro: INES, 2005.

KELMAN, Celeste Azulay. "Aqui tudo é importante!" Interações de alunos surdos com professores e colegas em espaço escolar inclusivo. Tese (Doutorado) - Programa de Pós-Graduação em Psicologia, Instituto de Psicologia, Universidade de Brasília, Brasília, 2006.

KELMAN, Celeste Azulay; FARIA, Cassiana Borges. Mães de surdos e suas percepções. In: MANZINI, Eduardo José (Org.) Inclusão do aluno com deficiência na escola: os desafios continuam. Marília: ABPEE/FAPESP, 2007. p. 187-200.

KELMAN, Celeste Azulay; BRANCO, Angela Uchôa (Meta)communication strategies in inclusive classes for deaf students. American Annals of the Deaf, Washington, Gallaudet University, v. 154, n. 4, p. 373-381. 2009.

LACERDA, Cristina Broglia Feitosa; SILVA, Daniele Nunes Henriques. Educação, surdez e inclusão social. Cedes, Campinas, Unicamp. v. 26, n. 69, maio-ago. 2006.

LURIA, Alexander Romanovich. Pensamento e linguagem: as últimas conferências de Luria. Porto Alegre: Artes Médicas, 1986.

RIBEIRO, Jorge Ponciano. A Resistência Olha a Resistência. Psicologia: Teoria e Pesquisa. v. 23 n. especial, p. 73-78, 2007.

SILVA, Daniele Nunes Henriques. Como brincam as crianças surdas. 2. ed. São Paulo: Plexus, 2007. TAVEIRA, Rose Mary. Privação auditiva precoce em crianças portadoras da Síndrome de Down e suas implicações para o desenvolvimento da linguagem. Dissertação (Mestrado em Psicologia) Universidade de Brasília, Programa de Pós-Graduação em Psicologia, Brasília, 1995.

VIGOSTKI, Lev Semenovich. Fundamentos de Defectologia. La Habana: Pueblo y Educación, 1989.

Recebida $2^{\mathrm{a}}$ versão em junho de 2011

Aprovada $2^{\text {a }}$ versão em agosto de 2011 
Celeste Azulay Kelman, doutora em Psicologia pela Universidade de Brasília. Professora do Programa de Pós Graduação da Faculdade de Educação da Universidade Federal do Rio de Janeiro. Publicação recente: Dilemas sobre o implante coclear: implicações linguísticas e pedagógicas (Espaço, v. 33, p. 33-41, 2010). E-mail: cel.azuldsuperig.com.br.

Daniele Nunes Henriques Silva, professora do Departamento de Psicologia Escolar e Desenvolvimento do Programa de Pós-Graduação em Processos de Desenvolvimento Humano e Saúde no Instituto de Psicologia da Universidade de Brasília, pesquisadora do grupo de pesquisa Pensamento e Linguagem (GPPL/UNICAMP). E-mail: daninunes74agmail.com

Ana Cecília Ferreira de Amorim, psicóloga pelo Centro Universitário de Brasília e mestranda do Programa de Pós-Graduação em Processos de Desenvolvimento e Saúde no Instituto de Psicologia da Universidade de Brasília. E-mail: aceciliafadgmail.com.

Daisy Cristina Azevedo, psicóloga pela Universidade de Marília. E-mail: daisycristinaađgmail.com.

Rosa Maria Godinho Monteiro, graduada em Pedagogia pela Universidade de Brasília. E-mail: rosaflormonteirodgmail.com. 


\section{Linhas Críticas}

A revista foi criada em 1995 com o objetivo de divulgar a produção científica de docentes e pesquisadores da Universidade de Brasília, como também editar artigos de autores de outros centros de investigação do Brasil e do exterior. Conta, desde o início, com um Comitê e Conselho Editorial qualificado, reconhecido nacional e internacionalmente. A partir de 2005 o periódico passou a contar com uma versão online na REDALYC - Red de Revistas Científicas de América Latina y el Caribe, España y Portugal, disponível em: www.redalyc.com.

\section{NÚMEROS TEMÁTICOS}

No 33 (vol. 17) Educação especial inclusiva

No 32 (vol. 17) Docência, formação e gestão

No 31 (vol. 16) Hermenêutica, teoria crítica e educação

No 30 (vol. 16) Educação profissional e tecnológica

No 29 (vol. 15) Formação de profissionais da educação

No 28 (vol. 15) Políticas educacionais e novas formas de regulação

No 26 (vol. 14) Docência na educação superior

No 24 (vol. 13) Educação e novas tecnologias

No 22 (vol. 12) Educação, formação e aprendizagem

No 21 (vol. 11) Edição comemorativa: 10 anos de Linhas Críticas

No 20 (vol. 11) Políticas públicas para a educação

No 18 (vol. 10) Gestão na educação

No 17 (vol. 9) Novas tecnologias na educação

No 16 (vol. 9) Educação especial

No 15 (vol. 8) Criatividade na educação

No 12 (vol. 7) Formação de professores e financiamento da educação

No 7-8 ( vol. 4) Psicodrama na educação

No 5-6 (vol. 3) Filosofia para crianças

No 3-4 (vol. 2) Faculdade de Educação da UnB: um ideário pedagógico à altura do Brasil 